\title{
EVALUATION OF PENETRATION DEPTH OF SODIUM HYPOCHLORITE INTO DENTINAL TUBULES AFTER PASSIVE ULTRASONIC IRRIGATION COMPARED TO ER;YAG LASER ACTIVATION. AN IN-VITRO STUDY
}

\section{ABSTRACT}

Objectives: The aim of this study was to compare penetration depth of sodium hypochlorite into dentinal tubules after passive ultrasonic agitation and ER; YAG activation.

Materials and methods:Twenty-four single rooted human mature mandibular premolars were decoronated and accessed. After locating the apex and determining the working length, preparation of root canal was done up to \#35 file using Mtwo system and with $5.25 \% \mathrm{NaOCl}$ irrigation. Teeth were then sealed apically with wax and submerged in a crystal violet dye for 48 hours to stain dentin. $\mathrm{NaOCl}$ Irrigation was activated with either Ultrasonic or ER;YAG laser. Specimens were sectioned longitudinally and depth of bleached zone was evaluated under a stereomicroscope 40X.

Results:Penetration depth was significantly higher in overall root canal in ultrasonic group than ER;YAG laser group ( $\mathrm{P}=.000)$. In ER;YAG Laser group, the highest penetration depth was in the coronal third followed by middle and apical, with significant difference between apical third and both middle and coronal thirds $(\mathrm{P}=.009, .003$ respectively), and no significant difference between middle and coronal thirds $(\mathrm{P}=.083)$. Highest penetration depth was seen in the middle third, followed by coronal and apical,withno significant difference in penetration depth between the three sections of the root canal activated with Ultrasonic $(\mathrm{P}=.664)$.

Conclusion: ultrasonic activation can lead to more $\mathrm{NaOCl}$ penetration into dentinal tubules than activation with ER;YAG.

Key words: Sodium Hypochlorite, Ultrasonics, ER;YAG Laser 


\section{INTRODUCTION}

Successful endodontic treatment is dependent on the proper cleaning and shaping of canals to eliminate the remnants of vital and necrotic tissues, microorganisms and their toxins, and accumulated dentinal debris resulting from instrumentation. Mechanical instrumentation alone is insufficient to disinfect the whole root canal system. ${ }^{1}$ A study conducted by Peterset $a .^{2}$ showed that $35 \%$ of the root canal remained untouched after instrumentation. Thus, chemical irrigation has an important complementary role in disinfecting rootcanals, which allows the penetration to dentinal tubules, isthmus, lateral canals, and apical ramifications. ${ }^{3,4}$

Sodium hypochlorite has been introduced to endodontics as the main and most common irrigant due to its antibacterial effect, the ability to dissolve organic tissues and pulpal residuals, and the penetration of lateral canals, which is attributed to its low viscosity. ${ }^{5-7}$

Traditional irrigation with a syringe and needle has limited penetration into lateral canals. ${ }^{8}$ Activating endodntic irrigants has deemed to increase the disinfecting properties of irrigants through the enhancement of its chemical and physical actions. ${ }^{9}$

Ultrasound was first introduced to Endodontics in $1957 .{ }^{10}$ Passive Ultrasonic Irrigation (PUI)can disinfect root canal through the improvement of irrigant contact to the root canal walls, and its cavitation and acoustic streaming effects. ${ }^{11}$ A review of the literature described the antibacterial effect of the PUI system, and its efficacy in better removal of the smear layer, facilitating cleaning the isthmus from curved root canals. ${ }^{12}$ The rapid movement of this device enhances the shear stress of tissue remnants and biofilm. ${ }^{13}$

More Recently, Laser activated irrigant (LAI) has gained attention in root canal irrigation. ${ }^{14} \mathrm{LAI}$ has the ability to enhance root canal debridement by its photoacoustic wave shocks in the irrigating which results in vaporization of the irrigant, creating vapor bubbles that can expand and explode with cavitation effect. Expansions cause high pressures which leads to the rupture of bubbles. $^{15}$

The literature yielded conflicting results regarding the most effective way in enhancing the penetration of $\mathrm{NaOCl}$ into dentinal tubules. While some studiesreported that laser activation is better than ultrasonic devices ${ }^{14,16}$, others stated opposite results ${ }^{17,18}$. Thus, the aim of this study was to compare PUI and ER;YAG (LAI) in penetration depth of $\mathrm{NaOCl}$ into dentinal tubules.

\section{MATERIALS AND METHODS}

This study was carried out at the department of Operative Dentistry, Faculty of Dentistry, Hama University, and an approval of the Scientific Research Committee of Hama University with the ID: 307 has been obtained on 14/2/2018 before the initiation of the study.

Sample size calculation was done using G*power program v.3.1 (Heinrich-HeinUniversitatDüsseldorf, Germany; http://www.gpower.hhu.de/), and 24 freshly extracted human mature single-rooted mandibular premolars were determined as the total specimens. Teeth were extracted due to orthodontic reasons.

Tooth selection criteria were as follows: single canal, no external or root internal resorption, lack of tooth caries, cracks or developmental anomalies under 20X magnification, and no previously endodontically treated canals, with canal curvature of no more than $5^{\circ}$ according to Schneider. ${ }^{19}$

Teeth were debrided using CK6 hand instrument (Zeffiro-Lascod, Florence, Italy) to remove all tissue debris attached to the root surface after extraction. Then, teeth were stored in a plastic container with $0.5 \%$ chloramine $\mathrm{T}$ for 1 week to sterilize the specimens, before they were moved to another plastic container with $0.9 \%$ saline and kept in a refrigerator at $4{ }^{\circ} \mathrm{C}$ until used.

\section{Sample preparation}

The crown of teeth were shortened using a diamond disk (Edenta, Switzerland) to standardize the length at $19 \mathrm{~mm}$ using a digital caliper.

Conventional access cavity was done using a $2 \mathrm{~mm}$ round bur, and the roof of the pulp chamber 
was removed with Endo-Z bur (Dentsply, Switzerland). The pulp of each tooth was extirpated with barbed broaches (VDW, Germany). The working length was measured after locating the apex with a $15 \# \mathrm{~K}$-file until the tip of the file was observed from the apical foramen, then subtracting $1 \mathrm{~mm}$ from the canal length.

\section{Root canal preparation}

Canals were prepared with Mtwo system (VDW; Germany) following the basic instrument sequence until \#35 along the entire working length using a gentle in and out motions. Preparation was done according to manufacturer's instruction regarding the speed and torque. $2 \mathrm{ml}$ of $5.25 \% \mathrm{NaOCl}$ was irrigated after each instrument and a final rinse with $5 \mathrm{ml} \mathrm{NaCl}$ was done before drying specimens with paper points.

The root surface of each tooth was covered with two layers of nail varnish, and the apical foramen was sealed in order to prevent the dye from leakage outside the canals.

A preliminary study was conducted in order to determine the most appropriate periodfor the type of sectioning (cross sectional vs. longitudinal), and the pigmentation process in which teeth were submerged in the crystal violet dye for 12 or 24 or 48 hours, and the final period was found to be the appropriate one to stain the hole root canal.

Specimens were submerged in a plastic container with crystal violet dye for 48 hours in $37^{\circ} \mathrm{C}$ temperature. Teeth were then washed with running water to flush away the dye.

\section{Study groups and irrigation protocols}

Specimens were randomly distributed into two groups based on the activation method as follows:

Group A ( $\mathrm{n}=12)$ : activation using ultrasonic device (Varios 350, NSK, Japan).

Group B ( $\mathrm{n}=12)$ : activated using ER:YAG laser (Kavo Key Laser III 1243, Germany).

In each group, $2 \mathrm{ml}$ of $5.25 \% \mathrm{NaOCl}$ was introduced for 60 secondsusing a 30-Gauge open ended needle $1 \mathrm{~mm}$ shorter of the apical foramen.
In group A: $2 \mathrm{ml}$ of $5.25 \% \mathrm{NaOCl}$ was introduced for 60 secondsusing a 30-Gauge open ended needle $1 \mathrm{~mm}$ shorter of the apical foramen. Ultrasonic activation was performed by inserting a stainless steel \#22 U file into E11 Ultrasonic tip (Varios, NSK, Japan) at E4 power to agitate irrigant for $60 \mathrm{~s}$ and $1 \mathrm{~mm}$ above the apical foramen. Root canal was irrigated then with $2 \mathrm{ml}$ of $5.25 \% \mathrm{NaOCl}$ for another $60 \mathrm{~s}$ and a final rinse was accomplished with saline for 60s. A final rinse with saline solution was applied for 60 seconds.

In group B: $2 \mathrm{ml}$ of $5.25 \% \mathrm{NaOCl}$ was introduced for 60 seconds using a 30-Gauge open ended needle $1 \mathrm{~mm}$ shorter of the apical foramen. ER:YAG laser was used for activation with a special fiber head designed for endodontic usage (100 mill joules, 2 watts, frequency: $20 \mathrm{~Hz}$ ) for 60s. Root canal was irrigated then with $2 \mathrm{ml}$ of $5.25 \% \mathrm{NaOCl}$ for another $60 \mathrm{~s}$ and a final rinse was accomplished with saline for 60s. A final rinse with saline solution was applied for 60 second.

\section{Teeth sectioning and measuring the depth of NaOCl penetration}

Teeth were sectioned longitudinally after creating a groove of $1 \mathrm{~mm}$ depth on the mesial and distal surface of the root under an endodontic microscope with 30x magnification. Then, each tooth was put on a polyvinyl siloxane model in order to separate the two sections with a chisel and a mallet. ${ }^{20}$

Two parallel lines, $3 \mathrm{~mm}$ apart, were drawn on the surface of each section to calibrate the image. Each section was captured with a digital camera (Samsung NX500, Samsung; USA) under a stereomicroscope (Meiji; Japan) at 40X. The depth of sodium hypochlorite penetration was measured using Microdicom Program by evaluating the whitened areas inside the dentinal tubules in each third (coronal, middle, apical) of the tooth, where the dye was removed due to the oxidization effect of sodium hypochlorite. (Fig1 and 2). 


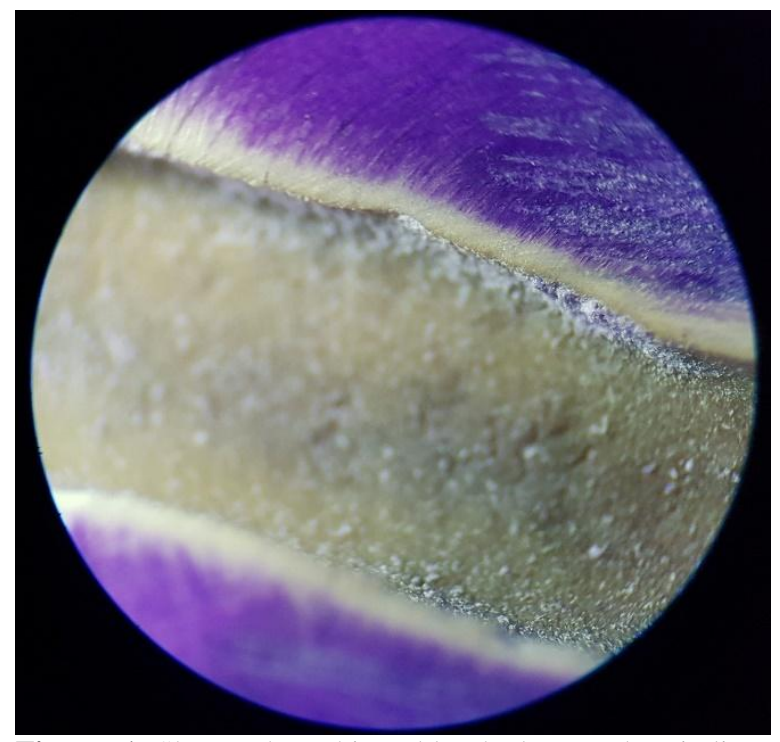

Figure 1 Shows the whiten bleached area that indicates penetration depth of $\mathrm{NaOCl}$ in PUI

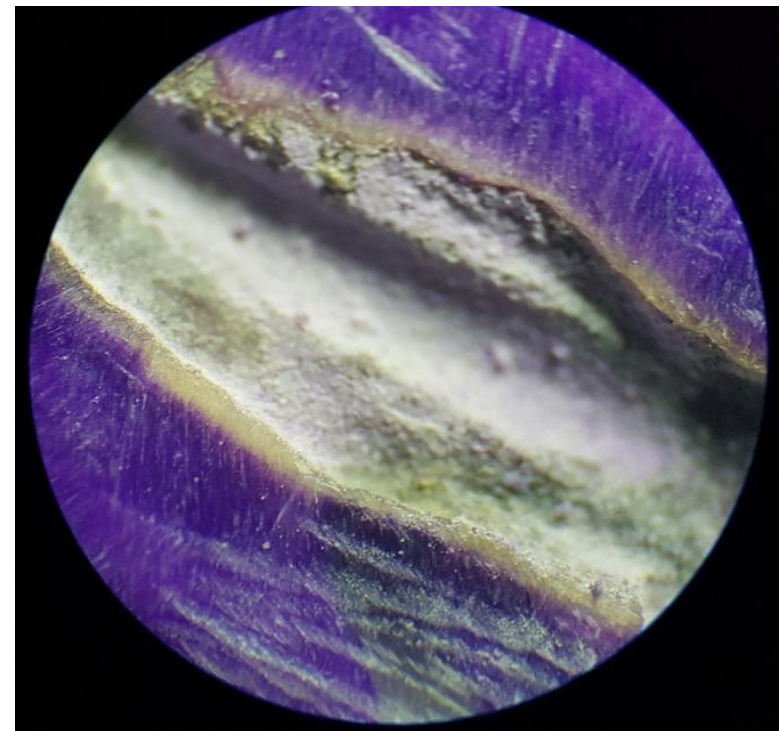

Figure 2 Shows the whiten bleached area that indicates penetration depth of $\mathrm{NaOCl}$ in LAI

\section{Statistical Analysis}

Normality of distribution was checked with Kolmogorov-Smirnov test. Data showed normal distribution. Thus, independent $\mathrm{T}$ test was used to determine if there was a statistically significant difference in $\mathrm{NaOCl}$ penetration depth betweengroupA and group $\mathrm{B}$ in each third (coronal, middle, third), and ANOVA test to determine if there was a statistically significant difference in the depth of penetration between the three sectionsof the root surfacewithin each group

Data were analyzed using SPSS V.23 (IBM; CORP., ARMONK, USA). The level of the P value was set $5 \%$, and the level of confidence was set at $95 \%$.

\section{RESULTS}

Descriptive results including minimum, maximum, mean, and standard deviation of $\mathrm{NaOCl}$ penetration depth in each third of the root surface and overall root canal surface areshown in (Table 1). Group A activated with ultrasonic showed more penetration depth in the three thirds of the root canal compared to groupB activated with ER:YAG laser.

Table1.Shows descriptive results of the Independent $\mathrm{T}$ test regarding the penetration depth of $\mathrm{NaOCl}$ between PUI amd LAI within each level of the root anal (coronal, middle, and apical third) in (mm)

\begin{tabular}{|c|c|c|c|c|c|}
\hline Levels & Activation type & $\min$ & $\max$ & mean \pm SD & P Value \\
\hline \multirow[t]{2}{*}{ Apical third } & PUI & 0.17 & 0.62 & $0.45 \pm 0.13$ & $.002 *$ \\
\hline & LAI & 0.1 & 0.62 & $0.25 \pm 0.14$ & \\
\hline \multirow[t]{2}{*}{ Middle third } & PUI & 0.25 & 0.86 & $0.62 \pm 0.18$ & $.003 *$ \\
\hline & LAI & 0.26 & 0.65 & $0.41 \pm 0.12$ & \\
\hline \multirow[t]{2}{*}{ Coronal third } & PUI & 0.32 & 1.03 & $0.59 \pm 0.24$ & .076 \\
\hline & LAI & 0.28 & 0.8 & $0.44 \pm 0.16$ & \\
\hline \multirow[t]{2}{*}{ Overall } & PUI & 0.17 & 1.03 & $0.55 \pm 0.20$ & $.000 *$ \\
\hline & LAI & 0.1 & 0.8 & $0.37 \pm 0.16$ & \\
\hline
\end{tabular}

\section{*significant difference}

SD- Standard Deviation

Independent $\mathrm{T}$ test showed significantly higher penetration depth in the apical, middle third, and overall root canal length in Ultrasonic group compared to ER:YAG laser group $(\mathrm{P}=$
$0.002,0.003,0.000$ respectively). No significant difference in penetration depth in the coronal third between the two groups $(\mathrm{P}=0.076)$ (Table 1). 
Descriptive results showed higher penetration depth in the middle third, followed by coronal, and apical third in group A. However,in group B, highest penetration depth was seen in coronal third followed by middle and apical thirds. (Table 2)

Table2. Shows descriptive results of the ANOVA test regarding the penetration depth of $\mathrm{NaOCl}$ between each level of the root anal (coronal, middle, and apical third) in PUI and LAI groups (mm)

\begin{tabular}{llllll}
\hline groups & Levels & min & max & mean \pm SD & P Value \\
\multirow{3}{*}{ PUI } & Apical third & 0.17 & 0.62 & $0.45 \pm 0.13$ & \\
& Middle third & 0.25 & 0.86 & $0.62 \pm 0.18$ & $.0006^{*}$ \\
& Coronal third & 0.32 & 1.03 & $0.59 \pm 0.24$ & \\
\multirow{2}{*}{ LAI } & Apical third & 0.1 & 0.62 & $0.25 \pm 0.14$ & \\
& Middle third & 0.26 & 0.65 & $0.41 \pm 0.12$ & .083 \\
\hline
\end{tabular}

*significant difference

SD- Standard Deviation

ANOVA test showed no significant difference in penetration depth of $\mathrm{NaOCl}$ between the three thirds of the root canal within group A (activation with Ultrasonic) $(\mathrm{P}=0.083)$. However, significant difference in penetration depth between the three thirds of the root canal within group $\mathrm{B}$ (activation with ER:YAG Laser) $(\mathrm{P}=0.006)$ (Table 2).
LSD Post hoc test for pairwise comparison in group B (activation with ER:YAG Laser) showed significant difference between apical third and both middle and coronal thirds $(\mathrm{P}=0.009,0.003$ respectively). No significant difference was observed between middle and coronal thirds $(\mathrm{P}=0.0664)$ (Table 3).

Table 3. LSD pairwise comparison between the three Levels of root canal in LAI group in (mm)

\begin{tabular}{|c|c|c|c|c|c|}
\hline group & & & $\begin{array}{c}\text { Difference in } \\
\text { means }\end{array}$ & SE & P Value \\
\hline \multirow{3}{*}{ LAI } & \multirow{2}{*}{ Apical third } & Coronal third & -0.18 & 0.06 & $.003^{*}$ \\
\hline & & Middle third & -0.16 & 0.06 & $.009^{*}$ \\
\hline & Middle third & Coronal third & -0.02 & 0.06 & .664 \\
\hline
\end{tabular}

SE -Standard Error

\section{DISCUSSION}

Bacteria of severely infected root canal can invade smear layer along the root canal into dentinal tubules in lateral canals and as a result be responsible of treatment failure. ${ }^{21}$ Smear layer can interfere with the penetration of irrigants and antimicrobial agents into dentinal tubules. ${ }^{22}$ Nair et $a l^{23}$ showed residual infection in mesial root canals of mandibular molars after instrumentation, irrigation with $\mathrm{NaOCl}$ alone, and obturation. Therefore, enhancement of irrigation by devices is important to allow irrigants to disinfect these

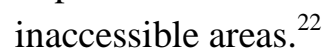

It has been declared that the presence of smear layer can impede the penetration of $\mathrm{NaOCl}$ into dentinal tubules. ${ }^{24}$

Olivi. ${ }^{25}$ explained the effect of Er;YAG laser on dentinal debris and smear layer removal, besides its ability to enhance the action of $\mathrm{NaOCl}$.This enhancement has been related to the shockwaves of lasers that can be absorbed through $\mathrm{NaOCl}$ creating vapor bubbles that can expand and implode reducing smear layer. ${ }^{26}$

On the other hand, Hazar et al. ${ }^{27}$ showed high efficacy of ultrasonic agitation in triple antibiotic paste removal from the apical portion of the root canal, which was related to the high velocity of irrigant flow, while Uzunoglu et al. ${ }^{28}$ showed that some ultrasonic dependent devices can have good effect in removing $\mathrm{CaOH}$ from root canal. In addition, ultrasonic can enhance irrigation through disinfection and smear layer removal through bubbles generated by cavitation and acoustic streaming effects. ${ }^{22}$ Therefore, this study aimed to compare activation of Er;YAG laser, and Ultrasonic in penetration depth of $\mathrm{NaOCl}$. 
Crystal violet dye was chosen in this study due to its high ability in pigment dentine so it can be easily seen under a stereomicroscope, and since $\mathrm{NaOCl}$ is an antioxidant it can whiten the purple color of the dye revealing the normal color of dentine.

This study assessed the penetration depth after sectioning teeth longitudinally with a chisel and a mallet, in order to maintain the inside portion of the root canal intact and preserveit from damage that could be attributed due to diamond disc sectioning.

Studies showed that bacteria can penetrate dentinal walls and lateral canals into different depths. ${ }^{29,30}$ In $62 \%$ of cases, bacteria can invade dentinal tubules and reach the surface of cementum. ${ }^{31}$ This bacteria can be responsible of endodontic treatment failure. ${ }^{32}$

With regards to activation with Er;YAG laser, this study showed highest penetration depth in the coronal third, followed by middle and apical third. Significant difference was seen between apical third and both middle and coronal thirds. This was consistent with Rajakumaran et $a l . .^{33}$ and Ghorbanzadeh et al. ${ }^{16}$ study that showed highest penetration depth with laser activated irrigant in coronal third followed by middle and apical thirds. Highest penetration depth in coronal third could be attributed to thelarge and densely packed dentinal tubules seen in the coronal thirdof the root canal followed by middle third, while narrower tubules are located more in the apical thirds, and as a result can limit the ability of irrigant penetration. ${ }^{34}$ Both groups demonstrated minimum penetration depth in the apical third of the root canal, this was in agreement with Ghorbanzade et $a l .{ }^{16}$, Macias et $a l^{35}$, and Vandrangi. ${ }^{36}$

However, interesting findings was observed in Ultrasonic activation, where the highest penetration depth was in middle third, followed by coronal and apical with no significant differences between the three thirds. This finding was in agreement with Vandrangi. ${ }^{36}$ Macias et al. ${ }^{35}$ also showed highest penetration of Chinese ink in the middle third of the root canal when ultrasonic was
used.In contrast, Baz et al. ${ }^{37}$ showed lower penetration depth in middle third than coronal. However, different irrigation protocols were used with up and down motions in activation, while in this study the PUI was set at one position.

This study showed that penetration depth of ultrasonic was significantly higher compared to Er;YAG laser in overall root canal length. Therefore, within the confines of this study, the use of expensive laser devices is not necessary. Moor et al. ${ }^{17}$ revealed that laser devices could be replaced with ultrasonic devices in order to remove smear layer, on condition that activation of ultrasonic should be for 60 seconds in total, which was similar time in the present study. Although Deleu and Meire ${ }^{18}$ revealed better smear layer removal in LAI than PUI, no significant difference was observed between the two groups.

This study was not consistent with Ghorbanzade et al. ${ }^{16}$ study which revealed that laser activation is better than ultrasonic with regards to penetration depth. However, this could be attributed to the different type of laser activation (Nd; YAG) used in their studies, and less activation times.Schlichting and Widbiller. ${ }^{14}$ showed better penetration when PIPS was used compared to ultrasonic, but this difference could be related to the irrigation regimen used in their study, where $\mathrm{NaOCl}$ was preheated in conjunction to the use of EDTA as a final irrigation protocol.

\section{CONCLUSIONS}

Passive ultrasonic agitation can be an effective irrigant activation method through enhancing the penetration depth of $\mathrm{NaOCl}$ into dentinal tubules more than ER;YAG laser.

\section{ACKNOWLEDGMENT}

This study has been carried out at the department of Operative Dentistry, Faculty of Dentistry, Hama University, Syria, which deserves a great appreciation for all academic and financial support.

\section{CONFLICTS OF INTEREST}

The authors declare no conflicts of interest. 


\section{REFERENCES}

1. Maciel Filho M, Zotarelli-Filho I, Linhares de Castro F. Main Predictors of Root Canal Endodontical Treatment: Systematic Review. Int J Dent Oral Sci 2018;5:595-600.

2. Peters OA, Schonenberger K, Laib A. effects of Ni$\mathrm{Ti}$ preparation technique on root canal geometry assessed by micro computed tomography. Int Endod $\mathbf{J}$ 2001;34:221-230.

3. Jena A, Sahoo SK, Govind S. Root canal irrigants: a review of their interactions, benefits, and limitations. Compend Contin Educ Dent 2015;36:256-261.

4. Ramachandra JA, Nihal NK, Nagarathna C, Vora MS. Root canal Irrigants in Primary Teeth. World J Dent 2015;6:229-234.

5. Ismail $\mathrm{S}$, Adyanthaya $\mathrm{A}$, Sreelakshmi N. Intracanal irrigants in pediatric endodontics : A review. Int J Appl Dent Sci 2017;3:246-251.

6. He L, Zhong J, Gong Q, Kim SG, Zeichner SJ, Xiang L, Ye L, Zhou X, Zheng J, Liu Y, Guan C, Cheng B, Ling J, Mao JJ. Treatment of Necrotic Teeth by Apical Revascularization: Meta-analysis. Sci Rep 2017;7:1-11.

7. Kuştarcı A, Oktay EA, Kılıç A, Özan Ü, Altunbaş D. Evaluation of antimicrobial efficacy of sodium hypochlorite, propolis, octenidinedihydrochloride and chlorhexidine on microorganisms. Cumhur Dent $\mathrm{J}$ 2011;14:183-190.

8. Buldur B, Kapdan A. Comparison of the EndoVac System and Conventional Needle Irrigation on Removal of the Smear Layer in Primary Molar Root Canals. Niger J Clin Pract 2017;20:1168-1174.

9. Walsh LJ. Activation of Alkaline Irrigation Fluids in Endodontics. Materials (Basel)2017;10:1-10.

10. Plotino G, Pameijer CH, Grande NM. Ultrasonics in Endodontics: A Review of the Literature. J Endod 2007;33:81-95.

11. Wright PP, Walsh LJ. Optimizing Antimicrobial Agents in Endodontics. In: Kumavath RN, (eds). Antimicrobial Agents. Croatia: InTech; 2017:87-107.

12. van der Sluis L, Versluis M, Wu M, Wesselink P. Passive ultrasonic irrigation of the root canal: a review of the literature. Int Endod J 2007;40:415-426.

13. Bryce G, MacBeth N, Gulabivala K. The efficacy of supplementary sonic irrigation using the EndoActiva- torâ system determined by removal of a collagen film from an ex vivo model. Int Endod $\mathbf{J}$
2018;51:489-497.

14. Schlichting R, Widbiller M. Penetration depth of irrigants into root dentine after sonic, ultrasonic and photoacoustic activation. Int Endod J 2019;52:12101217.

15. Plotino G, Cortese T, Grande NM, Leonardi DP, Di Giorgio G, Testarelli L, Gambarini G. New technologies to improve root canal disinfection. Braz Dent J 2016;27:3-8

16. Ghorbanzadeh A, Aminsobhani M, Chiniforush N, Shamshiri AR. Penetration Depth of Sodium Hypochlorite in Dentinal Tubules after Conventional Irrigation, Passive Ultrasonic Agitation and $\mathrm{Nd}$ :YAG Laser Activated Irrigation. Laser Appl Med Sci Res Cent 2016;7:105-111.

17. Moor RJG De, Meire M, Goharkhay K. Efficacy of Ultrasonic versus Laser-activated Irrigation to. J Endod 2010;36:1580-1583.

18. Deleu E, Meire MA. Efficacy of laser-based irrigant activation methods in removing debris from simulated root canal irregularities. Laser Med Sci 2013;30:831-835.

19. Schneider SW. A comparison of canal preparations in straight and curved root canals. Oral Surg Oral Medi Oral Pathol 1971;32:271-275.

20. Sabins RA, Johnson JD, Hellestein JW. A comparison of the cleaning efficacy of short- term sonic and ultrasonic passive irrigation after hand instrumentation in molar root canals. $\mathrm{J}$ Endod 2003;29:647-648.

21. William S, Goldman M. penetrrabilty of the smeared layerby a strain of Proteus vulgaris. J Endod 1985;11:385-388.

22.Zehnder M. Root Canal Irrigants. J Endod 2006;32:389-398.

23. Nair B, Reddy K. Advances in root canal disinfection. J Pharm Biomed Sci 2011;5:1-3.

24. Fogel H, Pashley D. Dentine pwemeability: effects of endodontic procedures on root slabs. J Endod 1990;16:442-445.

25. Olivi G. Laser Use in Endodontics : Evolution from Direct Laser Irradiation to Laser-Activated Irrigation. J Laser dent 2013;21:58-71.

26. George R, Walsh LJ. Apical Extrusion of Root Canal Irrigants When Using Er: YAG and $\mathrm{Er}, \mathrm{Cr}$ : YSGG Lasers with Optical Fibers: An In Vitro Dye Study. J Endod 2008;34:706-708. 
27. Hazar E, Sağlam BC, Koçak S, Koçak MM. Efficacy of XP-Endo Finisher and Passive Ultrasonic iRRIGATION on Modified Triple Antibiotic Paste Removal. Cumhur Dent J 2019;22:108-113.

28. Uzunoglu E, Gorduysus M, Nagas E. Efficacy of different devices in removing calcium hydroxide from the root canal. Cumhur Dent J 2015;18:318-326.

29. Schafer E, Bossmann K. antimicrobial efficacy of chlorohexidine and two calcium hydroxide formulations against Entrococcus fecalis. J Endod 2005;31:53-56.

30. Siqueira JF, Rocas I, Lopez H. patterns of microbial colonization in primary root canal infections. Oral Surgery, Oral Med Oral Pathol Oral Radiol Endodontology2002;93:174-178.

31. Peters L, Wesselink $P$, Buijs $J$, Winkelholf A. viable bacteria in root dentinal tubules of teeth with apical periodontitis. Int Endod J 2001;27:76-81.

32. Haapasalo M, Qrastavik D. in vitro infection and disinficton of dentinal tubules. J Dent Res 1987;66:1375-1379.
33. Rajakumaran A, Ganesh A. Comparative Evaluation of Depth of Penetration of Root Canal Irrigant After Using Manual, Passive Ultrasonic, and Diode Laser-Assisted Irrigant Activation Technique. J Pharm Bioallied Sci 2019;11:216-220.

34. Paqué F, Luder HU, Sener B, Zehnder M. Tubular sclerosis rather than the smear layer impedes dye penetration into the dentine of endodontically instrumented root canals. Int Endod J 2006;39:18-25.

35. Macías D, Bravo V, Echeverri D. Effect of sonic versus ultrasonic activation on aqueous solution penetration in root canal dentin. J oral Res 2018;7:2429.

36. Vandrangi P. Evaluating Penetration Depth of Treatment Fluids into Dentinal Tubules Using the GentleWave ${ }^{\circledR}$ System. Dentistry 2016;6:3-7.

37. Castelo-baz P, Cantatore G, Ru M. In Vitro Comparison of Passive and Continuous Ultrasonic Irrigation in Simulated Lateral Canals of Extracted Teeth. J Endod 2012;38:688-691. 